This work was supported by the Scientific and Research Committee of the Royal Infirmary, Newcastle.

Requests for reprints should be addressed to Dr. D. N. S. Kerr.

\section{References}

Anderson, M., Floyd, M., and Wardle, E. N. (1974). Kidney International. Submitted for publication.

Dixon, F. J. (1968). American fournal of Medicine, 44, 493.

Floyd, M., Shenton, B., and Swinney, J. (1973). British fournal of Experimental Pathology, 54,615 .

Lopez, C. et al. (1974). American fournal of Medicine, 56, 280.
McFarlane, A. S. (1963). Fournal of Clinical Investigation, 42, 346. Meltzer, M., and Franklin, E. C. (1969). American fournal of Medicine, 40,828 .

Tesar, J. T., and Schmid, F. R. (1970). Fournal of Immunology, 105, 1206 Takeda, Y. (1965). Fournal of Laboratory and Clinical Medicine, 1, 66 .

Vassalli, P., and McCluskey, R. T. (1971). Advances in Nephrology, vol. 1, p. 47. Chicago, Year Book Medical Publishers.

Wardle, E. N. (1972 a). Fournal of the Royal College of Physicians, 7, 5.

Wardle, E. N. (1972 b). Scandinavian fournal of Infectious Diseases, 4, 155

Wardle, E. N. (1973 a). Quarterly Fournal of Medicine, 165, 205.

Wardle, E. N. (1973 b). Clinical Science and Molecular Medicine, 45, 35.

Wardle, E. N. (1973 b). Clinical Science and Molecul

Wardle, E. N., and Floyd, M. (1973). British Medical fournal, 3, 255.

Wardle, E. N., Uldall, P. R., and Swinney, J. (1975). Transplantation. In press.

\title{
Haematemesis: A New Syndrome?
}

\author{
A. T. R. AXON, A. CLARKE
}

British Medical fournal, 1975, 1, 491-492

\section{Summary}

Three patients presented with symptoms suggesting a Mallory-Weiss tear. Endoscopy showed a localized, clearly demarcated area of bright red mucosa near the gastro-oesophageal junction; this was thought to have arisen by retrograde intussusception of the stomach during vomiting or retching and may have caused the haemorrhage.

\section{Introduction}

Since 1929, when Mallory and Weiss described gastrointestinal bleeding from gastric tears, several papers (Dobbins, 1963; Freeark et al., 1964; Holmes, 1966) have drawn attention to the frequency with which vomiting or retching may induce haemorrhage. The increasing use of early endoscopy in patients who are bleeding has shown that these lesions are even more common than was previously thought (St. John et al., 1974). The advantage of early endoscopy is that mucosal lesions, invisible on $x$-ray films, may be readily seen. Most papers have described longitudinal tears in the cardia which may extend into the oesophagus. Delumeau et al. (1972), however, described three patients in whom the lesions were atypical. We have recently seen three patients with a history suggestive of a Mallory-Weiss tear but who at endoscopy had a different but characteristic lesion at the cardia.

\section{Case 1}

A 41-year-old labourer was brought to the casualty department by the police in February 1974. He was too drunk to give a history but it appeared that while being questioned at the police station he had vomited blood. While in the casualty department he vomited coffee grounds. Four years previously a vagotomy and pyloroplasty had been performed for a perforated duodenal ulcer. He was a heavy drinker and had been admitted drunk to the casualty department on several occasions. His pulse rate was $80 / \mathrm{min}$ and his blood pressure

St. Thomas's Hospital, London SE1 7EH

A. T. R. AXON, M.D., M.R.C.P., Senior Registrar

Queen Alexandra Military Hospital, London SW1P 4RF

A. CLARKE, M.B., M.R.C.P., Senior Specialist in Medicine
$120 / 70 \mathrm{~mm} \mathrm{Hg}$. There was an abdominal scar. No melaena was found on rectal examination.

Next day endoscopy was carried out with an Olympus GIFD and JFB. The patient began to retch when the endoscope was inserted and stomach mucosa was seen to be forcibly projected up through the gastro-oesophageal opening. The prolapsed mucosa was bright red, and when the retching had stopped an angry red ring of mucosa was seen which encircled the upper end of the stomach. It had clearly defined edges and the appearances were those of an acute gastritis with severe inflammation. No other abnormality was seen apart from the changes of pyloroplasty.

\section{Case 2}

A 23-year-old warehouseman at a spirits firm was admitted to hospital in June 1974 complaining of left-sided abdominal pain for six hours. For four or five years he had been drinking about two bottles of spirits daily and had had several similar episodes of abdominal pain which had usually followed more extensive drinking bouts. The pain was colicky and tended to be relieved to some extent by vomiting. On this occasion, after drinking a bottle of whisky he developed abdominal pain and vomited normally several times but then had a haematemesis of about 0.51 . His pulse was $110 / \mathrm{min}$ and his blood pressure $110 / 85 \mathrm{~mm} \mathrm{Hg}$. There was moderate tenderness in the left iliac fossa. Rectal examination showed no melaena. He was thought to have sustained a Mallory-Weiss tear.

Twenty-four hours after the haematemesis endoscopy with an Olympus GIFD2 showed a localized area of bright, angry erythema in the upper part of the anterior wall of the stomach just below the oesophagogastric junction. The erythematous area was about $3 \mathrm{~cm}$ in diameter and had a clearly demarcated edge; the centre was superficially ulcerated. No other lesion was present in the oesophagus, stomach, or duodenum.

\section{Case 3}

A 35-year-old caretaker had a long history of repeated bouts of retching and abdominal pain often followed by small haematemeses. In 1972 he had a vagotomy and pyloroplasty for a duodenal ulcer. He admitted to smoking 25 cigarettes and drinking four bottles of beer a day.

In April 1974 he was referred for endoscopy 48 hours after a further bout of vomiting which culminated in a minor haematemesis. During the insertion of the endoscope, an Olympus GIFD2, he began to retch; bright red gastric mucosa was seen to prolapse into the lower oesophagus. When retching had stopped inspection of the stomach showed a clearly demarcated haemorrhagic area about $3 \mathrm{~cm}$ in diameter immediately below the gastro-oesophageal junction on the lesser curve. There was no obvious bleeding site or ulceration and no other abnormality was seen. Several biopsy specimens from the lesion showed mild oedema of the lamina propria only. 


\section{Discussion}

These patients had similar lesions. They differed in shape but their appearances were identical. All were situated in the upper part of the stomach within $5 \mathrm{~cm}$ of the cardio-oesophageal junction though not continuous with it. In each case there was an area of normal gastric mucosa interposed between the lesion and the cardio-oesophageal junction. The lesions were welldefined and the edge was abrupt, normal mucosa suddenly changing to bright red. The edges were regular and continuous; they were not wavy. Within the lesion the mucosa was uniformly bright red. This uniformity was characteristic. In some patients we have seen a blotchy redness in the stomach giving a morbilliform appearance. In the above cases, however, the mucosa was quite different; not only was it a much brighter red but the whole of the mucosa within the lesion was affected. There can be little doubt about the aetiology of the lesions. In cases 1 and 3 it was apparent that the act of dry retching had forced the gastric mucosa up into the oesophagus, where it formed a plug. The force with which this happened was considerable. Each patient had been vomiting frequently before endoscopy and these lesions must have arisen from friction of the gastric mucosa against the cardio-oesophageal junction. The shape and position of the lesion probably depends on which part of the stomach is forced into the cardio-oesophageal orifice. In case 1 a "ring" lesion was produced (fig. 1). In cases 2 and 3 "disc" lesions were observed (fig. 2).

It is more difficult to assess the role of these lesions in causing the haematemesis. Since two of the three patients had pre-

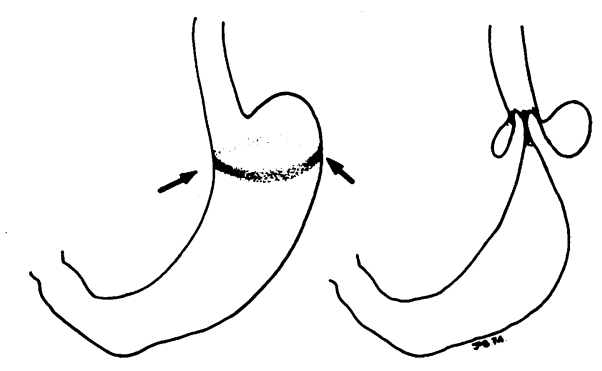

FIG. 1-Production of "ring" lesion. As intra-abdominal pressure rises stomach is invaginated and circumferential area of stomach is driven up into open lower end of oesophagus, where it acts as plug. This stops the vomit immediately and prolapsed stomach mucosa is traumatized on lower end of oesophagus.

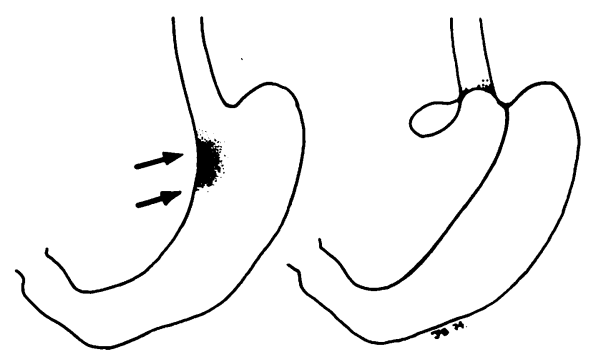

FIG. 2-Production of "disc" lesion. In this case only one side of stomach is driven into oesophagus and disc-like lesion results instead of circumferential one. viously had surgery for peptic ulceration and the postoperative stomach may be difficult to assess endoscopically (Cotton et al., 1973) possibly some stomal lesion could have been missed; we think this is unlikely. Another lesion that might have been overlooked is the Mallory-Weiss syndrome, which may be difficult to find, particularly if endoscopy is delayed. Nevertheless, good views of the upper gastrointestinal tract were obtained in each of the three patients and no other cause for haematemesis was found. Over the same period (four months) 43 patients underwent endoscopy for acute upper gastrointestinal bleeding. Thirty of these gave a history of vomiting and three had Mallory-Weiss tears but no patient showed both a definitive cause of the bleeding and the lesion described here.

This lesion is similar to the Mallory-Weiss syndrome in many ways. Its position in the upper part of the stomach, the association with alcohol (Dagradi et al., 1966), and the history of repeated retching and vomiting before the bleed all suggest a similar aetiology. The Mallory-Weiss syndrome is strongly associated with hiatus hernia (Atkinson et al., 1961; Dobbins, 1963). Of our patients one had a proved hiatus hernia and two had had a vagotomy, which predisposes to hiatus hernia (Tolstedt and Bell, 1964). But despite these similarities the mechanism whereby the lesion is produced must be quite different.

Mallory and Weiss (1929) and later Atkinson et al. (1961) performed experiments on cadavers which suggested that the gastric tear results from sudden distension of the upper part of the stomach. Atkinson et al. envisaged a failure of the lower oesophageal sphincter to relax together with herniation of the stomach into the thorax; the difference in pressure between the inside of the stomach and the thorax would cause sudden swelling of the intrathoracic portion of the stomach, stretching the mucosa and leading to a tear. Clearly this was not the mechanism in our cases, because if the lower oesophageal sphincter had failed to relax the stomach mucosa could not have been driven up into the gastro-oesophageal orifice. Retching in these cases almost certainly resulted form the stomach mucosa acting as a plug at the orifice during the attempt to vomit.

Delumeau et al. (1972) described three patients who presented with symptoms suggesting the Mallory-Weiss syndrome but in whom the lesion differed by the nature of its oval or round shape and by being generally more superficial. They called the lesion "isolated haemorrhagic ulceration of the cardia" (translation). Though the lesions we have seen could not be described as ulcers they may reprseent a similar lesion to those seen by Delumeau et al.

Requests for reprints should be sent to Dr. A. T. R. Axon.

\section{References}

Atkinson, M., et al. (1961). Gut, 2, 1.

Cotton, P. B., et al. (1973). British fournal of Surgery, 60, 629.

Dagradi, A. E., et al. (1966). American fournal of Digestive Diseases, 11, 710. Delumeau, G., et al. (1972). Annales de Gastroenterologie et d'Hepatologie, $8,329$.

Dobbins, W. O. (1963). Gastroenterology, 44, 689.

Freeark, R. J., et al. (1964). Archives of Surgery, 88, 882

Holmes, K. D. (1966). Annals of Surgery, 164, 810.

Mallory, G. K., and Weiss, S. (1929). American fournal of the Medical Sciences, 178, 506 .

St. John, D. J. B., et al. (1974). British Medical fournal, 1, 140.

Tolstedt, G. E., and Bell, J. W. (1964). American fournal of Surgery, 107, 895 